Facilitating Social Media and Offline Political Engagement During Electoral Cycles: Using Social Cognitive Theory to Explain Political Action Among Hispanics and Latinos

Alcides Velasquez, PhD. (Michigan State University) is an assistant professor in the Communication Studies Department at the University of Kansas. Bailey Hall

1440 Jayhawk Blvd., Room 102. Lawrence, Kansas 66045-7574. E-mail: avelasquez@ku.edu

Andrea Quenette, PhD. (Ohio State University) is an Assistant Professor in the Department of Communication Studies at Indiana University East. 2325 Chester Blvd. 115 TR Hall. Richmond, IN 47374. E-mail: aquenett@iu.edu 


\section{Facilitating Social Media and Offline Political Engagement During Electoral Cycles: Using Social Cognitive Theory to Explain Political Action Among Hispanics and Latinos}

Two interacting forces are subtly shifting the nature of American democracy - the public's increased use of social media for political information and meaningful changes in the demographic characteristics of the country. This study specifically examined ways in which social media use for political purposes could leverage greater offline political participation among Hispanics and Latinos - a rapidly growing segment of the population. Using Social Cognitive Theory, this study evaluated features of users' social media network and social media behaviors that can facilitate greater political participation both online and offline. Results indicate that individuals' social media network expression and social media political expression experiences influence users' social media political efficacy, social media political expression and eventually, their offline political engagement. Special attention is given to the role of social media political efficacy in promoting broad forms of social media political expression and offline engagement for Hispanics and Latinos.

Keywords: Social media, social cognitive theory, Hispanic/Latino, quantitative, survey 


\section{Facilitating Social Media and Offline Political Engagement During Electoral Cycles: Using Social Cognitive Theory to Explain Political Action Among Hispanics and Latinos}

A burgeoning literature has examined the relationship between different types of social media use and a variety of participatory political behaviors. Some of these studies have found a connection between political uses of social media and political participation during elections (Dimitrova, Shehata, Strömbäck, \& Nord, 2011); others, between informational social media use and both traditional and online forms of political engagement during electoral (Kushin \& Yamamoto, 2010) and off-electoral cycles (Gil de Zúñiga, Jung, \& Valenzuela, 2012). Moreover, studies have found a relationship between social interaction through social media and social media political expression and participation (Ekström \& Östman, 2013). But, how does social media use turn into social media political expression and participation? This study proposes a model that explains the mechanisms that connect social media use, social media political expression and traditional modes of electoral political participation based on Social Cognitive Theory (SCT) (Bandura, 1997).

The health of a democracy is not only measured in terms of the number of people who cast their votes during an election, but also by the level of engagement people show prior to an election date, and how involved they are with the different issues and policies discussed by candidates. For the past years, social media have become one of the preferred ways people get their news. According to a Pew Research Center report, around 67\% of American adults get their news through social media (Shearer \& Gottfried, 2017). Furthermore, as social media not only enables the diffusion of news, but also the expression of opinions, some people use it as a place for public expression and discussion of ideas (Smith, 2013b), and to influence others' views (Anderson, 2016). 
For these reasons, many see social media as a vehicle to channel and foster political activity. In fact, some argue that social media may have a mobilizing effect that can help reduce the existing participatory divides among individuals with lower socio-economic status (Enjolras, Steen-Johnsen, \& Wollebæk, 2012).

The differences in participation levels between ethnic and racial groups in the U.S., including voter turn-out, are notable. The case of Hispanics is notorious. While they currently are the biggest minority group in the U.S., with $17 \%$ of the entire population in the country, their participation levels lag behind non-Hispanic whites and non-Hispanic African Americans (Smith, 2013a). Moreover, during the elections of 2016, Hispanic/Latino voter turnout seemed to have declined (Lopez, Gonzalez-Barrera, Krogstad, \& López, 2016). Low participation levels also encompass political actions in which non-U.S. citizen Hispanics could also engage (DeSipio, 2006, p. 456), including political uses of social media (Smith, 2013a), despite Latinos being among the most avid users of this type of online platforms (Duggan \& Brenner, 2013). A number of concepts have been linked to individuals' political behaviors, but one with the most explanatory power remains political efficacy. Defined as individuals' belief that their political actions can have an impact and affect the political process (Campbell, Gurin, \& Miller, 1954; Craig, Niemi, \& Silver, 1990), political efficacy has been related to a number of political behaviors, such as deliberation (Morrell, 2005), voting (Karp \& Banducci, 2008) - including first time voting (Moeller, de Vreese, Esser, \& Kunz, 2014), and campaigning (Finkel, 1985). However, in this study we conceptualize efficacy under SCT, thus enabling an understanding of social media and offline political behaviors within a broader framework of human agency (Caprara, Vecchione, Capanna, \& Mebane, 2009). Although most commonly applied to the field of health communication, SCT can also help us understand the effects of mass communication 
on human behavior through modeling mechanisms (Bandura, 2001). More importantly, SCT not only accounts for observational learning and modeling effects but also self-effects through enactive experiences.

SCT defines self-efficacy in terms of perceived capabilities. This theoretical framework can also be used to uncover how the ever-increasing levels of social media use among Hispanics - a population historically politically disengaged - can facilitate political expression and action. Specifically, we argue that social media political efficacy (Velasquez \& LaRose, 2015) plays a mediating role; where social media use, together with the nature of individuals' prior political social media experiences (i.e. successful enactive experiences), and political expression of opinions through ones social network during the elections (i.e., vicarious learning) act as a source of efficacy, which consequently leads to social media political expression, and subsequently creates a path to offline participatory behaviors during the electoral cycle.

We collected data via an online survey of Hispanics in October 2016, during a tumultuous Presidential election. Participants who reported having either a Facebook or Twitter account were asked about their social media and political behaviors and attitudes. These data afford the opportunity to examine the interconnected relationships between social media political efficacy, social media use and political engagement.

\section{Literature Review}

\section{Social Media Political Efficacy and Social Media Political Expression}

SCT presupposes that humans are characterized by their will to exert control over what happens in their lives. This control is partly shaped by self-efficacy perceptions. Bandura defines selfefficacy as “... beliefs in one's capabilities to organize and execute the courses of action required to produce given attainments" (Bandura, 1997, p. 3). Hence, people that have high 
levels of efficacy in a particular realm of activity believe that they have greater control over their actions in that domain (Bandura, 1997, p. 36).

As people function in different domains, and these domains vary with regards to the knowledge and skills necessary to perform the activities that characterize it, perceptions of capability will vary in the different realms of human activity. Therefore, self-efficacy is defined as a context-dependent construct, based on the premise that people cannot be all things, nor can one master every realm of human activity (Bandura, 1997, p. 45). Self-efficacy as a cause of behavior and performance has been attested through a diversity of studies that include different populations, domains of functioning, and levels of performance (Bandura, 1997, p. 61).

Efficacy perceptions can be assessed at three different levels (Bandura, 1997, p. 49). The first one is the most specific assessment, which entails measurement of a specific behavior in a specific context or set of conditions. An intermediate level refers to behaviors within the same domain of activity and under a class of conditions that share similar properties. And finally, a global measure that does not define or specify the activities or the conditions in which the behavior is performed (Bandura, 1997, p. 49). Therefore, when trying to explain a specific level of performance in a given condition, a highly specific definition and measurement of efficacy is more optimal (Bandura, 1997, p. 49).

The distinction between the proposed concept of social media political efficacy and the traditional concept of political efficacy - as comprised by the two dimensions of internal and external political efficacy - is both operational and conceptual. The concept of internal political efficacy - defined as individuals' belief that their political actions can have an impact and effect a political process (Campbell et al., 1954) - is usually operationalized in terms of how individuals feel regarding their qualifications to participate in politics or to work in public office. 
However, someone can fully understand how a government or political system works, and at the same time lack a sense of efficacy to actually influence such system (Bandura, 1997, p. 484). Additionally, internal political efficacy, as usually measured, does not refer to capability judgments regarding specific political behaviors or modes of political participation. As such, internal political efficacy can be considered a global assessment of capability perceptions.

External political efficacy - the other dimension of the political efficacy construct - is defined as the perceived responsiveness that public officials and government institutions have to demands of citizens (Balch, 1974). Defined in this way, this concept does not refer to capability perceptions. Moreover, following what SCT tells us of efficacy perceptions, those that lack a sense of efficacy will most likely refrain from influencing a political system even if such system offers plenty of opportunities for exerting change. Conversely, those that believe in their capability to provoke change will try, despite few opportunities offered by the government (Bandura, 1997, p. 483).

The behavior and context under study here is political expression on social media. Social media are a place where people can enact their political selves, make public their opinions about political issues, or share with others information that can be useful to understand those issues better. We call this kind of online behavior social media political expression. Social media political expression presupposes individuals' interest in effecting the knowledge, information level, opinion, attitudes or behaviors of their social media contacts. However, the objective of controlling or influencing their social media political environment can be hardly pursued if they do not believe in their capability to perform the different activities needed to achieve that objective.

In a previous study, Velasquez and LaRose (2015) propounded the concept of social 
media political efficacy and its relationship with political uses of social media in student activist groups. They defined this concept as individual's beliefs that they can use social media for achieving their political objectives. Consistent with the proposed role of efficacy as a predictor of behavior, their findings showed that members who felt more capable of using social media to attain their political objectives were more likely to use social media for activism. Based on this evidence we hypothesize that:

H1: Social media political efficacy will be positively related to social media political expression.

\section{Sources of Social Media Political Efficacy Beliefs and Social Media Political Expression}

SCT favors a model of human nature and behavior based on triadic reciprocality (Bandura, 1986, p. 23). In this model, behavioral, cognitive and other personal and environmental factors influence each other reciprocally. In other words, each of these factors is caused by and causes the other factors in the model. However, reciprocity does not entail simultaneity, thus enabling the examination of how a specific influence or sequence of influences operate (Bandura, 1986, p. 25). In this study, we consider individuals' social media contacts' use of social media for political expression and individuals' own behavioral experiences using social media for political purposes as sources of individuals' social media political efficacy perceptions.

SCT tells us that vicarious experiences are one of the environmental factors that influence self-efficacy perceptions. Individuals appraise their capabilities in relation to what others have attained (Bandura, 1997, p. 86). People examine the attainments of others that are comparable to themselves and based on those attainments, make inferences about their own capabilities. In other words, people persuade themselves that if similar people have been able to perform at a certain level or execute certain actions successfully, they should also have the capabilities to 
follow those actions successfully and perform at that level; and therefore, behave accordingly.

We argue that the proposed influence of the environment manifests itself through the observation of individuals' social media contacts' successful use of social media for political expression. Individuals' observation of their social media contacts as they engage in such online behaviors influences a specific cognitive factor: social media political efficacy. Subsequently, as individuals feed their social media political efficacy perceptions by observing others' social media political use, they model that behavior in their own social media behaviors.

Findings in other studies can be interpreted along these lines. Velasquez (2012) found that previous participatory behavior of other users influenced individuals' commenting behavior in an online political community. Moreover, findings by Bond et al. (2012) also illustrate how the online political behavior of social media contacts influence individuals' own political actions. We propose an explanation of this relationship through social media political efficacy. We argue that the relationship between other users and individuals' social media expressive behaviors can be explained by the mediating role of social media political efficacy. We hypothesize that:

H2: Individuals' social media network political expression will be significantly related to social media political expression through social media political efficacy.

But the observation of other people's behaviors is not the only source of efficacy perceptions. Our own behaviors can also influence our own capability beliefs. Moreover, according to Bandura (1997, p. 80), enactive experiences are the most influential source of efficacy. When people are successful in performing a behavior and attaining an objective, they build-up their perceptions of what they can do. On the other hand, failing to achieve an objective undermines efficacy perceptions. People judge what they are capable of doing partly based on how they have fared previously in similar endeavors. A successful appraisal of prior experiences 
using social media for political expression will enhance social media political efficacy

perceptions, and subsequently influence positively social media political expression. Findings by Velasquez and LaRose (2015) support this idea. Their findings show how student activists who judged their previous use of social media for political purposes positively, also expressed feeling more capable of using social media for political activism.

Following this evidence and SCT propositions, we hypothesize that previous experiences judged as successful will influence social media political efficacy, and these will influence social media political expressive behaviors. We hypothesize that:

H3: Positive enactive experience will be significantly related to social media political expression through social media political efficacy.

\section{Social Media Use, Social Media Political Efficacy and Traditional Modes of Political Participation}

As mentioned previously, efficacy should be defined in relation to the specific context and behavior under study. However, Bandura argues as well that efficacy perceptions also have a certain degree of generality. Indeed, despite self-efficacy beliefs being defined as a function of a specific type of performance or context, they generate a set of mastery perceptions that can be generalized beyond the specificities of the context in question (Bandura, 1977).

In this sense, it can be argued that while social media political expression has a set of specificities given the online context in which it takes place, the efficacy perceptions they generate can also have implications for political behaviors outside the social media domain. We define political participation in this study as encompassing individuals' behaviors that seek to influence their political environment and conditions. Therefore, we argue that while social media political expression is a specific type of activity under specific conditions, it shares a set of 
properties with traditional modes of political participation, despite the differences in mode and context. In both types of political participation, individuals identify and take a position with regards to an issue or candidate, seek and find information that can support their position, are willing to elaborate arguments in favor of their position, and publicly voice their view. In other words, although both types of participation differ in the context in which they take place and in the activities that characterize them, the social media political efficacy beliefs necessary to use social media for political expression can be translated and applied to the demands of traditional modes of political participation.

In short, we argue that social media political efficacy, given its shared properties with traditional modes of political participation, should be related with political participation offline, both directly and indirectly, through social media political expression:

H4: Social media political efficacy will be positively related to offline political participation.

H5: Social media political expression mediates the relationship between social media political efficacy and political participation.

Additionally, since efficacy perceptions can be translated or applied to other domains or activities with similar properties, we argue that the previously observed relationship between overall social media use and offline participation (e.g., Valenzuela, Arriagada, \& Scherman, 2014), can be explained through increases in social media political efficacy beliefs. In the same way, individuals translate their social media political efficacy perceptions to the context of offline participation, the accumulated experience and frequent overall social media use creates a spillover effect between social media use and traditional modes of political participation (Vissers \& Stolle, 2014). With this hypothesis, we offer a theoretical explanation of the relationship 
between overall social media use and offline participation through gains in social media political efficacy beliefs.

H6: Social media use will be positively related to offline political participation through social media political efficacy.

Previous studies have also found a relationship between overall social media use and political participation through political uses of social media (Valenzuela, 2013). The explanatory mechanism in this relationship includes news exposure and consumption - either directly, by following news outlets on social media or by incidental exposure through a social media contact - or through interpersonal contact and exposure to others' opinions, conversations, political expressions elicited by news content, and exposure to individuals' mobilizing efforts (Valenzuela, 2013). This relationship is reflected through overall social media use, as more frequent use of social media leads to a higher probability of exposure to information and political expressions, and hence, gains in knowledge and interest about different political issues (Dimitrova et al., 2011). Knowledge and information gain processes might lead to more individual expression of views on such issues.

Another theoretical explanation of such relationship can be provided through modeling mechanisms. People observe others engaging in expressive behaviors online and decide to replicate them. Research that has examined users' online participation patterns suggest a social learning mechanism to explicate their participatory behaviors (Burke, Marlow, \& Lento, 2009). Consistent with previous findings, we seek to confirm that social media use creates a path to offline political participation through social media political expression:

H7: Social media use will be positively related to offline political participation through social media political expression. 


\section{Methods}

\section{Participants and Procedures}

To evaluate the hypotheses of interest in this study an online survey was conducted in October 2016, just prior to the Presidential election. Participants were recruited by Qualtrics, from their panel pool. The sample included only participants who self-identified as Hispanic or Latino and who also indicated they had either a Facebook or Twitter account $(N=227)$. Data used in this study were a part of a larger project including a general U.S. population sample, but those data are not included in analyses reported here. ${ }^{1}$

Participants were $67 \%$ female and the average age of the sample was 40.1 years $(S D=15$ years). The median education level was some college education, but less than a 2-year degree $(S D=1.5)$, and the median income level was between $\$ 40,000$ and $\$ 49,000$ annually $(S D=$ 2.89). The sample was liberal with $71.7 \%$ of participants either identifying as or leaning towards the Democratic Party.

After providing consent, participants completed an online survey including measures relevant to this study, among others. Data collection spanned October $26^{\text {th }}-28^{\text {th }}, 2016$.

\section{Measures}

Question wording for each measure is included in Appendix A.

Network political expression. Authors developed the items used to evaluate participants' network expression. The measurement was comprised of three items that asked participants about how many of their social media contacts (Facebook or Twitter) engaged in various political behaviors via social media $(M=2.61, S D=1.25, \alpha=.89)$.

Social media political expression. Individual's expression of political opinion or

\footnotetext{
${ }^{1}$ Institutional Review Board approval for this study was obtained October $10^{\text {th }}, 2016$
} 
affiliation was measured using four items adapted to the social media context from previous work on online political participation (Rojas \& Puig-i-Abril, 2009). The questions prompted participants to reflect on whether they engaged in specific behaviors during the 2016 election. Participants selected Yes or No for each question; these responses were then summed $(M=1.91$, $S D=1.55, \alpha=.80)$.

Successful Enactive Experience. This variable was measured using the scale developed by Velasquez and LaRose (2015). Participant's perceptions of their ability to use social media to engage in politics or express political opinions were measured using six Likert-scale items. Higher scores reflected more positive enactive experiences $(M=4.80, S D=1.19, \alpha=.81)$.

Social media political efficacy. The scale developed by Velasquez and LaRose (2015) was used to evaluate participant's efficacy in their use of social media for political aims. Participants indicated their level of confidence on a five-point scale - extremely confident to extremely not confident $(M=3.71, S D=1.01, \alpha=0.89)$.

Political participation. Political participation was gauged adapting the measurement used by Rojas and Puig-i-Abril (2009). It was comprised of nine items that focused on political behaviors participants were involved in within the previous 12-months. Behaviors participants had engaged in were scored as 1 and summed to create an overall score of political participation activity $(M=2.74, S D=3.2)$.

Social media use. Frequency of social media use was assessed using an index of four items. Scores on each of the four items were summed to create an overall measure of the amount of social media participation in which each participant engaged $(M=11.97, S D=5.19)$.

Controls: Four demographic variables discussed above (age, income, education, party identification) were included as controls in all analyses. Additionally, participant's level of 
political interest $(M=8.1, S D=3.0)$ was measured and included as a control in the model. Because gender was used as a weight for the sample, it was not possible to include participants' gender as a control (see Analytic Strategy below). Information about the ways in which the sample resembled the general Hispanic/Latino population on these control variables is included as Table 1.

\section{[TABLE 1 AROUND HERE]}

\section{Analytic Strategy}

All results stemmed from an SEM model evaluating the variables of interest in the hypotheses while controlling for five variables (age, income, education, party identification and political interest). Due to bias in the sample related to participants' gender, the sample was weighted to correct for this bias using 2016 predicted population values, derived from 2010 US Census data (U.S. Census Bureau, 2010). Females were weighted at 50.8 and males at 49.2.

Using Mplus, all estimates were obtained using 1000 bias-corrected bootstrapped samples. Based on the available fit indices, model fit was adequate $(\mathrm{SRMR}=.02)$. Additional fit indices were not available due to the use of sample weights to correct for the nonrepresentative nature of the gender distribution of the sample.

This model relied on bias-corrected bootstrapped sampling to estimate sample parameters and confidence intervals. The benefits of using such approaches include the ability to correct for non-normality in the data, better accuracy in hypothesis testing than relying on Type 1 error rates alone, and greater stability of parameter estimates (MacKinnon, 2008). This approach is also useful when population characteristics are unknown or unclear (MacKinnon, 2008).

However, it has also been argued that such techniques can artificially support relationships in the data that are not evident in the original dataset (MacKinnon, 2008). To test 
for such irregularities, the model was also run without any type of bootstrapped sampling. The model fit remained the same and all relationships remained stable. Based on this, we are confident use of bias-corrected bootstrapped sampling did not negatively impact our ability to make accurate predictions from the data.

Several theoretically plausible alternative models were tested. Based on a comparison of AIC values for the model reported here and these alternatives, model fit diminished significantly between the tested and alternative models. Details about the alternative models tested is available upon request.

For all findings, both unstandardized beta weights and 95\% confidence intervals are reported, and the tested model is included as Figure 1. A full table of the results, including the loadings of all control variables, is included as Table 2.

\section{[TABLE 2 AROUND HERE]}

[FIGURE 1 AROUND HERE]

\section{Results}

Each of the seven hypotheses was tested using the SEM model described above. H1 examined the link between social media political efficacy and social media political expression. This relationship was significant; those who were more confident in their ability to use social media for political aims effectively were more likely to express political opinions on social media $(b=.32,[.11, .56])$.

Similarly, it was predicted that social media network political expression was significantly indirectly related to social media political expression through social media political efficacy. Although the loading approached significance $-\mathrm{H} 2$ was not supported $(b=.01,[-.02$, 0.05]). However, there was a direct effect between network political expression and social 
media political expression, providing partial support for $\mathrm{H} 2(b=.31,[.13, .46])$.

Turning to the influence of positive enactive experience, those who had greater positive experiences using social media for political purposes were also more likely to express their political views on social media, but through social media political efficacy $(b=.16,[.05, .29])$. A greater number of positive experiences led to feelings of greater efficacy which facilitated social media political expression. H3 was supported.

H4 tested the relationship between social media political efficacy and offline political participation. Results indicated this relationship was significantly predicted in the model. Those who were more confident in their ability to effectively use social media for political purposes were also more likely to participate in politics offline, supporting $\mathrm{H} 4(b=.53,[.18, .92])$.

Social media political efficacy also indirectly influenced offline political participation, through the effect of social media political expression. Greater confidence in one's ability to use social media for political purposes led to increased social media political expression which in turn, drove offline political engagement. H5 was supported $(b=.21[.08, .42])$.

Finally, ones' general frequency of social media use was predicted to be positively related to offline political participation through both social media political efficacy (H6) and social media political expression (H7). Both of these hypotheses were supported. More frequent use of social media was associated with individuals' greater confidence in their ability to effectively use social media for politics $(b=.02,[.01, .04])$ as well as increased use of social media to express political opinions $(b=.05[.03, .09])$.

\section{Discussion}

In the search for levers that can effectively mobilize voters, findings from this study suggest several factors that can potentially facilitate offline political participation among 
Hispanics - a rapidly growing segment of the population with high adoption of social media but lagging levels of political engagement. Results discussed above suggest five key mechanisms that either directly or indirectly influence offline political participation among this demographic group -1) one's general social media use, 2) observation of how users' own social network use social media for political purposes, 3) one's successful experiences using social media for political purposes, 4) perceptions of social media political self-efficacy and, 5) social media political expression. Together, these constructs comprise a picture of how interacting within an online social network and individuals' social media political behaviors influence offline engagement - demonstrating a positive influence on participation (Delli Carpini, 2000) in an increasingly fragmented political environment (Shah et al., 2017).

While previous theories of social media use and political participation have suggested a direct relationship between these two, we found support for an indirect effect through social media political efficacy beliefs. Evidence shows that general social media use influences political participation through social media political efficacy, adding new evidence to suggest spill-over effects of social media on individuals' political engagement (Cantijoch, Cutts \& Gibson, 2016). More importantly, while this theoretical model was tested with a sample of Hispanic/Latinos in the U.S., this evidence complements previous findings that point at the potential leveling effect social media use can play for populations that have been traditionally at the margins of political participation (Enjolras et al., 2012; Xenos, Vromen, \& Loader, 2014), acting as a gateway for political engagement.

We examined how the behaviors of their social media contacts influence individuals' own social media political behaviors through social media political efficacy. Although we did not find support for a mediated relationship through social media political efficacy, individuals' 
contacts did influence their social media political expression directly. While we did not examine individuals' online social network composition, evidence still points at behavioral modeling effects. Social cognitive theory suggests that behavioral modeling is more likely present when people observe similar others' behaviors and the positive outcomes of those behaviors (Bandura, 1997). This may indicate that those Hispanic/Latinos who are part of more homogenous social networks experience a stronger effect of others' social media behavior on their own social media political expression behavior. However, while we did not test this moderating effect of network characteristics, future studies should pay attention to this particular aspect.

After controlling for social media use, successful experiences using social media for political purposes also exerted a positive influence on social media political expression through social media political efficacy. By learning what they are capable of doing through their own prior social media experiences, Hispanics/Latinos likely feel a greater sense of control over their ability to use social media for political purposes, and therefore, use these media for political expression. This evidence contributes to similar findings in previous studies (Velasquez and LaRose, 2015), and goes beyond by further suggesting that these successful experiences, as perceived by users, lead to political engagement offline. The path moving from successful enactive experiences to political engagement through social media political efficacy and then through social media political expression, illustrates the value of social media environments for self-effects processes.

In sum, we show how individuals' social media environment, their own social media behaviors, and personal attributes create a path to offline political engagement. As participation in politics has remained low and stagnant, compared to other democratic nations, we uncovered a set of factors and processes that can boost engagement among the rapidly growing Hispanic 
population. Furthermore, results from this study indicate social media can facilitate political outcomes far beyond an individual's private home. During the turbulent 2016 Presidential election what happened online did not exclusively stay online - instead what users learned and observed from their social network impacted their online and offline political behaviors suggesting an important pathway to promoting political engagement among Hispanics and Latinos in the U.S.

Findings in this study also contribute to the broader theoretical discussion regarding the relationship between media and political participation. Within the mass media effects tradition, relationships have been regarded as capable of influencing individuals' attitudes and behaviors. In the theory, the proposed routes through which media and communication influence individuals are direct, through exposure to media messages, and indirect, through their social contacts. In the existing models that apply social cognitive theory, media and communication effect individuals' expected outcomes through the observation of others' experiences, their behavior through modeling and observational learning, and finally through efficacy, using vicarious experiences and persuasion as a source (Bandura, 2001; Pajares, Prestin, Chen, \& Nabi, 2009).

The novelty in this study is the incorporation of enactive as well as vicarious experiences as sources of efficacy. In this case, the effect is not caused by exposure to media content, but rather by individuals' own behavior and experiences interacting with others and reacting to the content they encounter on these platforms. Furthermore, the production of messages and communication enabled by the interactive and user-generated content capabilities of social media facilitate the emergence of an environment where individuals' own behaviors generate certain conditions where their personal attributes and behaviors are affected, in part, by the response of 
the environment they experience on social media sites.

\section{Limitations and Future Directions}

As the findings of this and prior work suggest (Velasquez \& LaRose, 2015), social media political efficacy perceptions play an important role in how the public enacts politics online. These behaviors, in turn, influence their offline engagement which is normatively beneficial for our democracy. Although data reported here did not show a relationship between network social media behaviors and social media political efficacy, it would be worthy to examine other features of an individual's network, the social media platform or other factors that might influence individuals' confidence in their ability to use social media for political aims.

In an attempt to test the theoretical relationships in the study, our measures used aggregates of both social media political expression and offline political participation. However, it is likely that different types of self-efficacy perceptions differently influence these behaviors and as such, different online expression behaviors have a unique influence on various forms of offline participation. Similarly, although voting is often the focus of political participation studies, the timeframe for data collection did not allow for the investigation of voting behavior here. Future work should drill down into the influence of social media political efficacy and online political behaviors on more specific online and offline behaviors and, on voting outcomes.

Furthermore, an individual's vicarious experiences and the ability to model the political engagement behaviors of one's social network, are a function of the nature of the individuals comprising the network. Future work should examine the role of network diversity and heterogeneity on a variety of factors, including political affiliation, political attitudes and demographic characteristics on perceptions of social media political efficacy and online and offline political engagement. As discussed above, it may be the case that the effects of others on 
efficacy and expressive behaviors are stronger when perceived similarities are higher.

In this study, we opted for a definition and operationalization of efficacy perceptions at a high level of specificity, as precedent research (Wollman \& Stouder, 1991) has shown that measures of efficacy beliefs regarding the specific mode of participation have more predictive value than global efficacy measures. This approach did not pretend to exclude or ignore the rich body of research that suggests a positive relationship between internal political efficacy and political participation. Rather, it seeks to contribute to our current understanding of the role that political efficacy plays in explaining different political behaviors - such as those emerging modes of participation supported by social media platforms. This model demonstrates how efficacy - referenced to a specific behavior in a specific context - can explain the process by which social media behaviors drive political expression and engagement online and offline.

Although the decision to exclude the traditional concept of internal political efficacy as a mediator in the relationship between social media political expression and political participation could be construed as a limitation, this decision was made in order to remain consistent with our conceptualization of efficacy, and not fall into the imprecision of either measuring it partially or not measuring it at all (Bandura, 1997, p. 484). We acknowledge that previous findings suggest how social media expression influences global political efficacy perceptions (e.g., Halpern, Valenzuela, \& Katz, 2017; Moeller et al., 2014; Zhou \& Pinkleton, 2012). Furthermore, we believe it is imperative to understand the way in which global and specific measures of political efficacy are related, which conceptualizations have greater explanatory value and for which modes of political participation, as well as to develop measures of internal political efficacy at a higher level of specificity. New studies should tackle this issue.

Finally, the sample was heavily skewed in terms of political affiliation. Although not 
explicitly tied to the variables of interest in this study, previous research has suggested that liberals and conservatives engage with politics differently (Carraro, Castelli, \& Negri, 2016; Wang, 2016), suggesting the possibility of differing influence of perceptions of political information encountered online. Research has not explored whether political affiliation similarly influences political engagement online, although future work should examine the influence of ideology on perceptions of social media political efficacy, and online and offline political engagement.

Lastly, these data are derived from a cross-sectional survey, rather than based on longitudinal modeling across time. Future work should examine the cyclical nature of political attitudes, social media perceptions and political participation with longitudinal data and method triangulation.

\section{Conclusions}

Hispanics and Latinos represent a demographic group that while technologically savvy, remains less politically engaged than whites and non-Hispanic racial and ethnic groups in the U.S (DeSipio, 2006). Findings of this study suggest that through social media engagement, this group can develop their sense of confidence in their abilities, giving them greater motivation to delve into the political system. By observing others' experiences and behaviors, engaging in greater social media use and feeling efficacious in the use of social media for political purposes, Hispanics are more likely to express their political opinions online and engage in political opportunities offline. By encouraging and even facilitating these types of meaningful and positive online experiences, there exists an opportunity to bolster broader political engagement amongst a diverse segment of the population. 


\section{References}

Anderson, M. (2016, November 7). Social media causes some users to rethink their views on an issue. Retrieved September 15, 2017, from http://www.pewresearch.org/facttank/2016/11/07/social-media-causes-some-users-to-rethink-their-views-on-an-issue/

Balch, G. I. (1974). Multiple indicators in survey research: the concept "sense of political efficacy." Political Methodology, 1(2), 1-43.

Bandura, A. (1986). Social foundations of thought and action. Englewood Cliffs, N.J.: Prentice Hall.

Bandura, A. (1997). Self-Efficacy: The Exercise of Control. Worth Publishers.

Bandura, A. (2001). Social cognitive theory of mass communication. Media Psychology, 3(3), $265-299$.

Bandura, Albert. (1977). Self-efficacy: Toward a unifying theory of behavioral change. Psychological Review, 84(2), 191-215. https://doi.org/10.1037/0033-295X.84.2.191

Bialik, C. (2016, November 15). No, Voter Turnout Wasn't Way Down From 2012. Retrieved September 18, 2017, from https://fivethirtyeight.com/features/no-voter-turnout-wasntway-down-from-2012/

Bond, R. M., Fariss, C. J., Jones, J. J., Kramer, A. D. I., Marlow, C., Settle, J. E., \& Fowler, J. H. (2012). A 61-million-person experiment in social influence and political mobilization. Nature, 489(7415), 295-298. https://doi.org/10.1038/nature11421

Burke, M., Marlow, C., \& Lento, T. (2009). Feed me: motivating newcomer contribution in social network sites. In Proceedings of the 27th international conference on Human factors in computing systems (pp. 945-954). New York, NY, USA: ACM. https://doi.org/10.1145/1518701.1518847 
Campbell, A., Gurin, G., \& Miller, W. E. (1954). The voter decides. Evanston, Ill.: Row, Peterson.

Caprara, G. V., Vecchione, M., Capanna, C., \& Mebane, M. (2009). Perceived political selfefficacy: Theory, assessment, and applications. European Journal of Social Psychology, 39(6), 1002-1020. https://doi.org/10.1002/ejsp.604

Carraro, L., Castelli, L., \& Negri, P. (2016). The hand in motion of liberals and conservatives reveals the differential processing of positive and negative information. Acta Psychologica, 168(Supplement C), 78-84. https://doi.org/10.1016/j.actpsy.2016.04.006

Craig, S. C., Niemi, R. G., \& Silver, G. E. (1990). Political efficacy and trust: A report on the NES pilot study items. Political Behavior, 12(3), 289-314. https://doi.org/10.1007/BF00992337

Delli Carpini, M. X. (2000). Gen.com: Youth, civic engagement, and the new information environment. Political Communication, 17(4), 341-349. https://doi.org/10.1080/10584600050178942

DeSilver, D. (2017, May 15). U.S. trails most developed countries in voter turnout. Retrieved September 18, 2017, from http://www.pewresearch.org/fact-tank/2017/05/15/u-s-voterturnout-trails-most-developed-countries/

DeSipio, L. (2006). Latino civic and political participation. In Hispanics and the Future of America (pp. 447-478). Washington, D.C.: National Academies Press.

Dimitrova, D. V., Shehata, A., Strömbäck, J., \& Nord, L. W. (2011). The effects of digital media on political knowledge and participation in election campaigns: Evidence from panel data. Communication Research. https://doi.org/10.1177/0093650211426004 
Duggan, M., \& Brenner, J. (2013). The Demographics of Social Media Users - 2012. Pew Internet \& American Life Project. Retrieved from http:/www.pewinternet.org/Reports/2013/Social-media-users/The-State-of-SocialMedia-Users/Overview.aspx

Ekström, M., \& Östman, J. (2013). Information, interaction, and creative production: The effects of three forms of Internet use on youth democratic engagement. Communication Research. https://doi.org/10.1177/0093650213476295

Enjolras, B., Steen-Johnsen, K., \& Wollebæk, D. (2012). Social media and mobilization to offline demonstrations: Transcending participatory divides? New Media \& Society. https://doi.org/10.1177/1461444812462844

Finkel, S. E. (1985). Reciprocal effects of participation and political efficacy: A Panel analysis. American Journal of Political Science, 29(4), 891-913.

Gil de Zúñiga, H., Jung, N., \& Valenzuela, S. (2012). Social media use for news and individuals’ social capital, civic engagement and political participation. Journal of ComputerMediated Communication, 17(3), 319-336. https://doi.org/10.1111/j.10836101.2012.01574.x

Halpern, D., Valenzuela, S., \& Katz, J. E. (2017). We face, I tweet: How different social media influence political participation through collective and internal efficacy. Journal of Computer-Mediated Communication, 22(6), 320-336. https://doi.org/10.1111/jcc4.12198

Karp, J. A., \& Banducci, S. A. (2008). Political efficacy and participation in twenty-seven democracies: How electoral systems shape political behaviour. British Journal of Political Science, 38(02), 311-334. https://doi.org/10.1017/S0007123408000161 
Kushin, M. J., \& Yamamoto, M. (2010). Did social media really matter? College students' use of online media and political decision making in the 2008 election. Mass Communication and Society, 13(5), 608-630. https://doi.org/10.1080/15205436.2010.516863

Lopez, M. H., Gonzalez-Barrera, A., Krogstad, J. M., \& López, G. (2016, October 11). 1. Latino voter interest and engagement in 2016. Retrieved September 18, 2017, from http://www.pewhispanic.org/2016/10/11/latino-voter-interest-and-engagement-in-2016/

Moeller, J., de Vreese, C., Esser, F., \& Kunz, R. (2014). Pathway to political participation: The influence of online and offline news media on internal efficacy and turnout of first-time voters. American Behavioral Scientist, 58(5), 689-700. https://doi.org/10.1177/0002764213515220

Morrell, M. E. (2005). Deliberation, democratic decision-making and internal political efficacy. Political Behavior, 27(1), 49-69. https://doi.org/10.1007/s11109-005-3076-7

Pajares, F., Prestin, A., Chen, J., \& Nabi, R. L. (2009). Social cognitive theory and media effects. In R. L. Nabi \& M. B. Oliver (Eds.), The SAGE Handbook of Media Processes and Effects (pp. 283-298). Thousand Oaks, CA, US: SAGE.

Rojas, H., \& Puig-i-Abril, E. (2009). Mobilizers mobilized: Information, expression, mobilization and participation in the digital age. Journal of Computer-Mediated Communication, 14(4), 902-927.

Shah, D. V., McLeod, D. M., Rojas, H., Cho, J., Wagner, M. W., \& Friedland, L. A. (2017). Revising the communication mediation model for a new political communication ecology. Human Communication Research, n/a-n/a. https://doi.org/10.1111/hcre.12115 
Shearer, E., \& Gottfried, J. (2017, September 7). News use across social media platforms 2017. Retrieved September 8, 2017, from http://www.journalism.org/2017/09/07/news-useacross-social-media-platforms-2017/

Smith, A. (2013a). Civic Engegement in The Digital Age. Pew Internet \& American Life Project. Retrieved from http:/www.pewinternet.org/Reports/2013/Civic-Engagement/Summaryof-Findings.aspx

Smith, A. (2013b, February 20). Digital politics: Pew Research findings on technology and campaign 2012. Retrieved October 13, 2017, from http://www.pewinternet.org/2013/02/20/digital-politics-pew-research-findings-ontechnology-and-campaign-2012/

Smith, A., Schlozman, K. L., Verba, S., \& Brady, H. (2009, September 1). The current state of civic engagement in America. Retrieved January 19, 2016, from http://www.pewinternet.org/2009/09/01/the-current-state-of-civic-engagement-inamerica/

United States Elections Project. (2016). 2016 November general election turnout rates. Retrieved September 18, 2017, from http://www.electproject.org/2016g

U.S. Census Bureau. (2010). The Hispanic population: 2010. Retrieved October 13, 2017, from https://www.census.gov/library/publications/2011/dec/c2010br-04.html

Valenzuela, S. (2013). Unpacking the use of social media for protest behavior: The roles of information, opinion expression, and activism. American Behavioral Scientist. https://doi.org/10.1177/0002764213479375 
Valenzuela, S., Arriagada, A., \& Scherman, A. (2014). Facebook, Twitter, and youth engagement: A quasi-experimental study of social media use and protest behavior using propensity score matching. International Journal of Communication, 8(0), 25.

Velasquez, A. (2012). Social media and online political discussion: The effect of cues and informational cascades on participation in online political communities. New Media \& Society, 14(8), 1286-1303. https://doi.org/10.1177/1461444812445877

Velasquez, A., \& LaRose, R. (2015). Social media for social change: Social media political efficacy and activism in student activist groups. Journal of Broadcasting \& Electronic Media, 59(3), 456-474. https://doi.org/10.1080/08838151.2015.1054998

Vissers, S., \& Stolle, D. (2014). Spill-over effects between Facebook and on/offline political participation? Evidence from a two-wave panel study. Journal of Information Technology \& Politics, 11(3), 259-275. https://doi.org/10.1080/19331681.2014.888383

Wang, C.-H. (2016). Personality traits, political attitudes and vote choice: Evidence from the United States. Electoral Studies, 44(Supplement C), 26-34. https://doi.org/10.1016/j.electstud.2016.07.004

Wollman, N., \& Stouder, R. (1991). Believed efficacy and political activity: A test of the specificity hypothesis. Journal of Social Psychology, 131(4), 557-566. https://doi.org/Article

Xenos, M., Vromen, A., \& Loader, B. D. (2014). The great equalizer? Patterns of social media use and youth political engagement in three advanced democracies. Information, Communication \& Society, 17(2), 151-167.

https://doi.org/10.1080/1369118X.2013.871318 
Zhou, Y., \& Pinkleton, B. E. (2012). Modeling the effects of political information source use and online expression on young adults' political efficacy. Mass Communication and Society, 15(6), 813-830. https://doi.org/10.1080/15205436.2011.622064 
Table 1. Sample demographic and political interest characteristics compared with population characteristics for Hispanics and Latinos

\begin{tabular}{lcc} 
Demographic Characteristic & Sample & Population \\
\hline Gender & $67 \%$ female & $49.5 \%$ female* \\
Age (Median) & 37.0 years & 28.9 years* \\
Education (Median) & Some college education & Some college education* \\
Income (Median) & $\$ 40,000-\$ 49,000$ annually & $\$ 47,675$ annually* \\
Party identification & $71 \%$ Democrat & $64 \%$ Democrat $* *$ \\
Political interest $(5 p t$ scale) & $M=3.7, S D=1.4$ & $M=2.8, S D=.8^{* * *}$
\end{tabular}

*U.S. Census Bureau (2016). Sex by Educational Attainment for the population 25 and over (Hispanic or Latino). American Fact Finder American Community Survey. Accessed online 222-18 at:

https://factfinder.census.gov/faces/tableservices/jsf/pages/productview.xhtml? src=bkmk ** Lopez, M., Gonzale-Barrera, A., Krogstad, J. \& Lopez, G. (2016). Latinos and the political parties. Pew Research Center Hispanic Trends. Accessed online 2-22-18 at: http://www.pewhispanic.org/2016/10/11/latinos-and-the-political-parties/.

*** Fraga, L. R., et al. (2006). Latino National Survey (LNS). Ann Arbor, MI: Inter-university Consortium for Political and Social Research [distributor], 2013-06-05.

https://doi.org/10.3886/ICPSR20862.v6 
Table 2. Loadings and confidence intervals for all predicted paths in the Structural Equation Model used to test all hypotheses

\begin{tabular}{|c|c|c|c|}
\hline Dependent Variables & Independent Variables & Estimate & $\begin{array}{l}95 \% \\
\text { Confidence } \\
\text { Interval }\end{array}$ \\
\hline \multirow[t]{8}{*}{$\begin{array}{l}\text { Social media political } \\
\text { expression }\end{array}$} & $\begin{array}{l}\text { Social media network political } \\
\text { expression }\end{array}$ & .31 & {$[.13, .46]$} \\
\hline & Social media political efficacy & .32 & {$[.11, .55]$} \\
\hline & Social media use & .08 & {$[.03, .12]$} \\
\hline & Education & -.01 & {$[-.11, .10]$} \\
\hline & Age & -.00 & {$[-.02, .01]$} \\
\hline & Party identification & .06 & {$[-.03, .14]$} \\
\hline & Income & -.03 & {$[-.08, .03]$} \\
\hline & Interest & .11 & {$[.05, .17]$} \\
\hline \multirow[t]{8}{*}{$\begin{array}{l}\text { Social media political } \\
\text { efficacy }\end{array}$} & $\begin{array}{l}\text { Social media network political } \\
\text { expression }\end{array}$ & .03 & {$[-.06, .12]$} \\
\hline & Successful enacted experience & .52 & {$[.41, .61]$} \\
\hline & Social media use & .04 & {$[.02, .06]$} \\
\hline & Education & .00 & {$[-.06, .06]$} \\
\hline & Age & -.01 & {$[-.01, .00]$} \\
\hline & Party identification & .02 & {$[-.03, .07]$} \\
\hline & Income & .00 & {$[-.03, .04]$} \\
\hline & Interest & .01 & {$[-.01, .04]$} \\
\hline \multirow[t]{8}{*}{ Offline political participation } & $\begin{array}{l}\text { Social media network political } \\
\text { expression }\end{array}$ & .67 & {$[.47, .92]$} \\
\hline & Social media political efficacy & .53 & {$[.18, .92]$} \\
\hline & Social media use & .06 & {$[.01, .13]$} \\
\hline & Education & .19 & {$[-.01, .41]$} \\
\hline & Age & -.02 & {$[-.04, .00]$} \\
\hline & Party identification & -.22 & {$[-.42,-.04]$} \\
\hline & Income & .05 & {$[-.05, .17]$} \\
\hline & Interest & -.11 & {$[-.22,-.00]$} \\
\hline
\end{tabular}


Figure 1. SEM model examining the role of social media content on efficacy and online and offline political engagement.

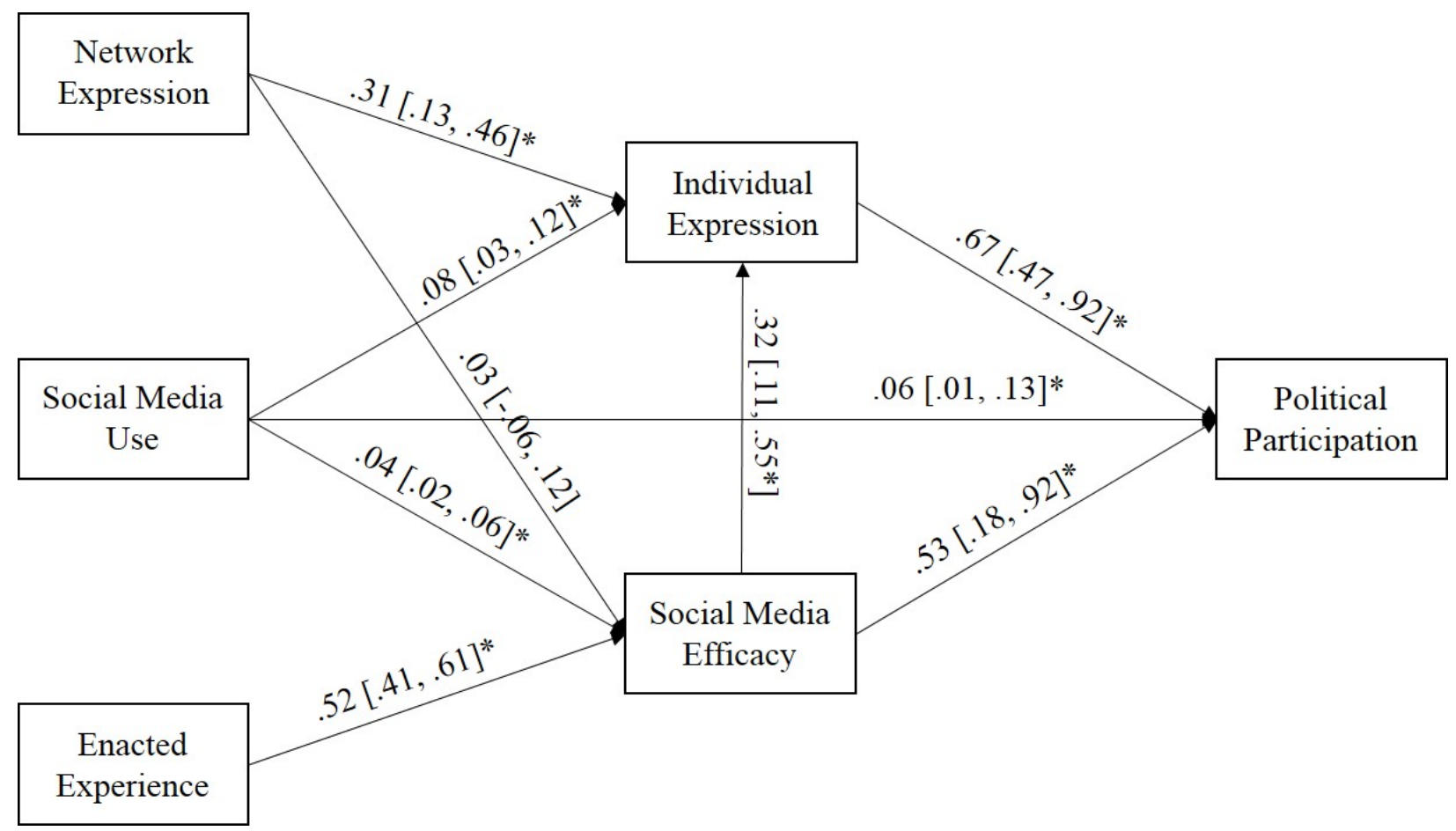

Note: Beta weights and 95\% Confidence Intervals are reported. See Table 2 for loadings and confidence intervals for all predicted paths. 
Appendix A: Question wording for all measures (excluding controls)

\section{Network political expression:}

During this presidential election about how many of your social media contacts (Facebook or Twitter) have:

Liked or followed one of the candidates' pages?

Posted their political stance on key campaign issues?

Revealed which presidential candidate they voted/will vote for?

Response scale: A great deal, a lot, a moderate amount, a little, none at all

\section{Social media political expression:}

During this presidential election how often have you engaged in the following behaviors?

Liked or followed one of the candidates' pages?

Posted candidates' political stance on key campaign issues?

Revealed which presidential candidate you support?

Posted your own personal thoughts or opinions about a particular candidate or party?

Response scale: Yes, No

\section{Successful enactive experience:}

How much do you agree or disagree with the following statements?

My personal experience has showed me that social media can be useful for political expression.

I have had the personal experience of successfully using social media for political activities.

I have not seen for myself that I can use social media for political expression (R).

I have been successful in using social media to interact with others around political issues. matters.

I have had successful experiences using social media to influence others on political

I have seen by myself that I can get important political information through social media. Response scale: Strongly agree, agree, agree somewhat, neither agree nor disagree, somewhat disagree, disagree, strongly disagree

\section{Social media political efficacy:}

How confident do you feel about your ability to do the following activities using social networks such as Facebook or Twitter?

Express your views about political issues.

Influence other people about political issues.

Discuss political issues with others effectively.

Response scale: Extremely confident, somewhat confident, neither confident or not confident, somewhat not confident, extremely not confident

\section{Political participation:}

In the last 12 months have you... Please check all that apply. 
Attended a political rally

Attended a public meeting of your city

Participated in a local municipal council

Signed a petition

Signed a petition

Called in a live radio or television show to express your opinion

Donated money or other objects to a political party or movement

Donated money or other objects to a group that does social or environmental work

Attended a social or political protest

Protested by blocking a street

Stopped buying a product or service, because you disagree with the politics of the company that provides it.

Other

Response scale: Yes, No

Social media use:

How often do you:

Check Facebook

Post on Facebook

Check Twitter

Post on Twitter

Response scale: Several times a day, once a day, 2 or 3 times per week, once a week, once a month, never 